\title{
Interactions between microplastics and phytoplankton aggregates : Impact on their respective fates
}

\author{
Long Marc ${ }^{1}$, Moriceau Brivaela ${ }^{1,{ }^{*}}$, Gallinari Morgane ${ }^{1}$, Lambert Christophe ${ }^{1}$, Huvet Arnaud ${ }^{2}$, \\ Raffray Jean ${ }^{1}$, Soudant Philippe ${ }^{1}$
}

${ }^{1}$ IUEM, UMR CNRS Ifremer IRD UBO 6539, Lab Sci Environm MARin LEMAR, F-29280 Plouzane, France.

${ }^{2}$ Ifremer, France

* Corresponding author : Marc Long, email address : moriceau@univ-brest.fr

\begin{abstract}
:
Plastic debris are resistant to degradation, and therefore tend to accumulate in marine environment. Nevertheless recent estimations of plastic concentrations at the surface of the ocean were lower than expected leading the communities to seek new sinks. Among the different processes suggested we chose to focus on the transport of microplastics from the surface to deeper layers of the ocean via phytoplankton aggregates that constitute most of the sinking flux. Interactions between microplastics and aggregates were studied by building a new device: the flow-through roller tank that mimics the behaviour of laboratory made aggregates sinking through a dense layer of microplastics. Three types of aggregates formed from two different algae species (the diatom Chaetoceros neogracile, the cryptophyte Rhodomonas salina and a mix) were used as model. With their frustule made of biogenic silica which is denser than the organic matter, diatom aggregates sunk faster than R. salina aggregates. Diatom aggregates were on average bigger and stickier while aggregates from $R$. salina were smaller and more fragile. With higher concentrations measured in R. salina aggregates, all model-aggregates incorporated and concentrated microplastics, substantially increasing the microplastic sinking rates from tenths to hundreds of metres per day. Our results clearly show that marine aggregates can be an efficient sink for microplastics by influencing their vertical distribution in the water column. Furthermore, despite the high plastic concentrations tested, our study opens new questions regarding the impact of plastics on sedimentation fluxes in oceans. As an effect of microplastic incorporation, the sinking rates of diatom aggregates strongly decreased meanwhile sinking rates of cryptophyte aggregates increased.
\end{abstract}




\section{Highlights}

- Flow-through roller tank: a new equipment to study aggregation Comparing diatom and cryptophyte aggregate characteristics and sinking rates - Phytoplankton aggregates incorporate and concentrate $2 \mu \mathrm{m}$ polystyrene microbeads. Microplastic sinking is strongly increased by incorporation in aggregates.

\section{Abbreviations}

- ESD, equivalent spherical diameter;

- MP, microplastic;

- SE, Standard Error;

- TEP, transparent exopolymer particles

Keywords: Microplastic sink, Vertical export, Diatom and cryptophyte aggregates, Settling rate, Permeability 


\section{Introduction}

Plastics are highly persistent materials that tend to accumulate in the environment. As the plastic industry grows, plastic debris are becoming more and more abundant and can be found in every ocean. For example, an increase in microplastic concentrations has been reported in the Pacific Subtropical Gyre over the last 30 years (Wright et al., 2013). Microplastics, defined by the US National Oceanic and Atmospheric Administration (Wright et al., 2013) as particles smaller than 5 $\mathrm{mm}$, are a large but mainly ignored portion of the plastic debris. Two main categories of microplastics (MP) have been defined depending on their origin. Primary MP originate from cosmetics, paints, textiles in household wastewaters or as pellets from plastic industry. Secondary MP result from macroplastic (size bigger than $5 \mathrm{~mm}$ ) fragmentation mainly caused by UV, waves or physical abrasion (Andrady et al., 2011). Like other plastic debris, MP are observed in all parts of the ocean, from the surface layer to the sediment (Claessens et al., 2011; Graham and Thompson, 2009; Mohamed Nor and Obbard, 2014; Thompson et al., 2004), as deep as 4844 meters in Porcupine abyssal plain (Van Cauwenberghe et al., 2013) and also in diverse levels of the trophic web (Dantas et al., 2012, Eriksson et al., 2003, Jantz et al., 2013). Common techniques and mesh sized used for MP sampling at sea limit measurements to debris bigger than $333 \mu \mathrm{m}$ (Deltares, 2011), however data on smaller MP particles are becoming available (Desforges et al., 2014, Mohamed Nor et al., 2014). Concentrations of MP have been found as high as 10000 particles $\mathrm{m}^{-3}$ on the Belgian coast (Van Cauwenberghe et al., 2014) and even 102000 particles $\mathrm{m}^{-3}$ in Swedish waters (Norén, 2007). MP repartition depends on various anthropogenic parameters, such as plastic inputs and human activity (marine transport, plastic industry, tourism, wastewater...), as well as environmental parameters like biofouling, hydrodynamics, wind, currents, local climate conditions and even seasonal variations (Barnes et al., 2009; Lima et al., 2014). Models based on MP data and on hydrodynamics have attempted to explain MP distribution and transport in the surface (Law et al., 2010) or in the bottom (Ballent et al., 2013) layers and have shown significant seasonal changes linked to climatic conditions. Recent studies also revealed low plastic concentrations at sea in comparison with expectations (Cózar et al., 2014, Eriksen et al., 2014) and suggested that deep sea 
may be a major sink (Woodall et al., 2014). Our understanding of the MP would clearly benefit from a better comprehension of the fate of these particles.

Vertical fluxes of plastics are not only dependent on the density of the particles, for example hydrodynamics can re-suspend MP from the benthos or mix particles from the surface into the water column (Collignon et al., 2012). But most of the time sinking is linked to density and MP particles with high densities are transported downward, while buoyant ones (46\% of plastic particles according to US EPA, Environmental Protection Agency, 2006) mostly stay at the surface (Barnes et al., 2009). Processes like biofouling can modify the density of particles and buoyant particles may sink to the bottom because of an increase in density due to colonization by microorganisms (Barnes et al., 2005). Among these are microalgae, which have been found attached to MP particles (Zettler et al., 2013). This sticking ability has been demonstrated by Bhattacharya et al. (2010) and Long et al. (2014). Many algae excrete polysaccharides especially at high cell concentrations or when they are stressed for example by light and nutrients limitation (Staats et al. 2000, Passow 2002, Underwood et al. 2004). Exopolysaccharides may coagulate due to turbulence to form sticky particles named transparent exopolymer particles (TEP) (Engel et al., 2000; Passow et al., 2002) and with sufficient stickiness, collision between microalgae and TEP result in cell aggregation. While some large microalgae can sink as free cells, most of the time aggregates are the main vessel for vertical transport of phytoplankton cells and detritus to the ocean floor (Moriceau et al., 2007; Thornton et al., 2002; and Turner, 2002; Kranck and Milligan, 1988). MP could potentially be incorporated into marine aggregates (Wright et al., 2013), which would constitute a vertical pathway for MP through the water column. In addition, marine aggregates are an important source of food for phytoplankton grazers and higher trophic levels and the incorporation of MP in aggregates and their transfer to the sea floor may have significant impact on marine biota. Such ingestion of plastics by marine organisms has been demonstrated at different level of the food chain (Boerger et al., 2010; Carson et al., 2013; Cole et al., 2013; Farrell et al., 2013; Fossi et al., 2012; Graham and Thompson, 2009).

This study aims to evaluate the impact of algae aggregation on MP repartition/distribution and vertical fluxes as well as the impact of MP on aggregate sinking rates. Two species of microalgae were selected for exposure to MP: the diatom Chaetoceros neogracile and the cryptophyte Rhodomonas salina. The first is known to form aggregates (Alldredge et al., 1988) and both are known to stick on large MP (Zettler et al., 2013). A specially designed flow-through roller tank, derived from the traditional roller tanks used for aggregation experiments (Shanks and Edmondson, 1989) was constructed for this study. 


\section{Material and methods}

\section{Flow-through roller tank}

The flow-through roller tank is a hybrid between the roller tank commonly used to promote aggregation since Shank and Edmondson (1989) and a flow through reactor often used in dissolution studies (Chou and Wollast, 1984; Rickert et al., 2002; Van Cappellen and Qiu, 1997). The flow-through roller tank (figure 1) was built by modifying the roller tank as described by Shank and Edmondson (1989). The tank was drilled on both flat side. The holes were diametrically opposed to avoid that the inflow solution was immediately pumped out, allowing the best mixing possible of the inflow with the tank water. Each opening was connected with a compact non-spill valve (1/8 hose barb valved panel mount coupling insert in Acetal, provided by Colder Product Company). Each valve was connected via a Tygon® tube, to another connexion made of two different parts: a 1/8 hose barb valved panel mount coupling insert stucked on the center of each side that turn with the tank. The latter is eventually coupled (not shown on figure 1) to a 1/8 hose barb valved panel mount coupling body (in Acetal, provided by Colder Product Company). This last valve is fixed to the roller table allowing the free rotation of the tank while the Tygon® tube connected to the peristaltic pump is kept immobile. Through this last Tygon® tube, the peristaltic pump injects a constant flow of solution with a known composition and flow rate. Using this experimental system, aggregates are continuously sinking in a medium that can be progressively renewed and controlled. This technique also allows sampling of the medium without creating turbulence or bubbles that may disrupt aggregates and their sinking. Aggregates were formed in these tanks in a first step without flow. Later in the experiment, a very low flow rate that renews the tank water in 6 hours $(4 \mathrm{~L} / 6 \mathrm{~h})$ was used and the sinking dynamic of aggregates maintained in the flow-through roller tank was not changed. In particular no changes in trajectory or deflection, even close to the input/output of flow were observed.

\section{Experimental protocol}

Phytoplankton cultures: Rhodomonas salina (cryptophyceae of $12 \mu \mathrm{m}$ ) and Chaetoceros neogracile (bacillariophyceae of $5 \mu \mathrm{m}$ ) obtained from the Scottish Marine Institute were grown in $\mathrm{f} / 2$ medium (Guillard et al., 1975) prepared in filtered $(0.22 \mu \mathrm{m})$ seawater from the bay of Brest (Brittany, France) with a density of $1.025 \mathrm{~kg} \mathrm{~L}^{-1}$. Cells were grown in $6 \mathrm{~L}$ glassware round bottom flasks at $16^{\circ} \mathrm{C}$, under a $12 \mathrm{~h} / 12 \mathrm{~h}$ photoperiod and an irradiance of $92 \pm 13 \mu \mathrm{mol}$ photons $\mathrm{m}^{-2} \mathrm{~s}^{-1}$. Once cultures reached the stationary phase, i.e. when the cell concentration remained stable, the cells were maintained in the dark for few days to provoke light limitation stress, expected to promote TEP excretion. Three different mixtures were prepared. The first two were monocultures: one with 


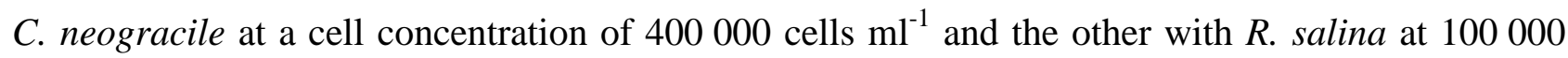
cells $\mathrm{ml}^{-1}$. The third was a combination of the two cultures with $C$. neogracile at $160000 \mathrm{cells} \mathrm{ml}^{-1}$ and $R$. salina at 300000 cells $\mathrm{ml}^{-1}$.

Aggregate formation: In three sequential experiments, each of the three mixtures of algae were transferred to two $5460 \mathrm{ml}$ cylindrical tanks for aggregation trials. One was the flow-through roller tank and the other a non-modified roller tank (Shank and Edmondson, 1989). During aggregation, the two tanks were kept in the dark at $16^{\circ} \mathrm{C}$. Motorized roller tables, as described in Moriceau et al. (2007), maintained a speed of 1.6 rotations per minute, keeping the aggregates in suspension and allowing collisions by differential sinking rates between particles as they were continuously sinking. No flow was going through the flow-through roller tank during the aggregate formation phase and aggregates formed in the two tanks were similar.

Aggregate exposure to MP: Once aggregates formed, the flow-through roller tank was connected to flow and a solution of microbeads $(2 \mu \mathrm{m}$ polystyrene microbeads,yellow-green fluorescent, density $1.050 \mathrm{~kg} \mathrm{~L}^{-1}$, provided by Polysciences Inc) at a concentration of $10^{4}$ beads $\mathrm{mL}^{-1}$ was injected. The microbeads solutions were injected within the flow-through roller tank using a peristaltic pump with an inflow of $680 \mathrm{ml}$ per hour. Careful observation allowed verifying that such flow was low enough to avoid aggregate trajectory deflection, even close to the input/output. Previous tests showed that no detectable amount of microbeads stuck to the system, and that the temporal evolution of the microbeads concentration in the tank was predictable. Aggregates were continuously exposed to the linearly increasing concentrations of microbeads during 6 hours with a concentration reaching 5500 microbeads $\mathrm{mL}^{-1}$ in the tank after six hours. Then, during a six hour dilution phase, the injected microbeads suspension was replaced by filtered $(0.22 \mu \mathrm{m})$ seawater containing no microbeads, linearly lowering the tank concentration to 2200 microbeads $\mathrm{mL}^{-1}$. During both, exposure and dilution phases, microbeads concentrations and free microalgal cell concentrations in outflows were monitored every hour by flow cytometry as described below. In parallel, the non-modified tank was kept in rotation in the same room under the same environmental conditions.

Flow cytometry: microalgae and microbeads were counted on a FACS Calibur flow cytometer with an argon blue laser (excitation $488 \mathrm{~nm}$ ) and Cellquest software. Cells and microbeads concentrations were estimated using particle counts and flow rate, measured according to Marie et al. (1999). Measurement of flow rate was done before each series of analysis. Microalgal populations were recognized according to their forward scatter (FSC) (related to particle size), side scatter (SSC) (related to the complexity of the particle) and their fluorescence in FL3 (red emission filter long pass, > $670 \mathrm{~nm}$ ) related to the chlorophyll content. Meanwhile microbeads were 
identified by their SSC, FSC and green fluorescence in FL1 (green emission filter band pass, 530 / $30 \mathrm{~nm})$.

\section{Aggregate characterisation: sampling and analysis}

At the end of the experiment, tank rotation was stopped and tanks were gently laid down on the table to let aggregates sink to the bottom of the tank before sampling. Firstly, pictures of the tank were taken to enumerate the total number of aggregates. Aggregates are fragile and sampling was performed carefully with a serological pipette which conical tip had been sawed off according to aggregate size (approximately $10 \mathrm{~mm}$ of opening diameter). Between fifty and hundred aggregates per tank were sampled to measure size and sinking rates. Ten aggregates per tank were carefully sampled in a Petri dish to measure their size using scaled paper, then microbeads and cells concentrations were measured by flow cytometry after extraction as described below.

Sinking rate and size of aggregates: Sinking rates were assessed in filtered seawater at room temperature $\left(16^{\circ} \mathrm{C}\right)$ using a graduated glassware cylinder. Sinking rates and sizes of aggregates were measured by video recording using a camera Canon Eos 600D. Pictures from the video were then extracted with the software Irfanview. Aggregate size was estimated by measuring height and diameter of each aggregate on pictures with the software Image $J$, calibration of size measurement by image analysis was made using scaled paper on side of the graduated cylinder. Aggregates obtained in our experiments were not spherical, but shape was close to prolate spheroid. Volume $(V)$ and equivalent spherical diameter $(E S D)$ were approximated using equations 1 and 2 respectively, as commonly used for a prolate spheroid in which depth equals width (Hillebrand et al., 1999):

$$
V=\frac{\pi}{6} \times d^{2} \times h
$$

$E S D=\sqrt[3]{\frac{6 \times V}{\pi}}$

Where $\mathrm{d}$ is the aggregate diameter, $\mathrm{h}$ is the aggregate's height, and $\mathrm{h}>\mathrm{d}$.

Microbeads and cells concentrations: After measuring their diameter and height using a scaled paper underneath the Petri dish, each of the ten individual aggregates collected was then transferred into a tube containing one milliliter of seawater. Aggregates were vigorously shaken to break them and homogenize the mixture. Cells and microbeads were counted by flow cytometry as described above.

Permeability: Brinkman permeability factor $\xi$ of all aggregates was derived from the single-particlefractal model by Li and Logan (2001) according to equation 3: 
$\xi=4.2\left(\frac{E S D}{d_{c}}\right)\left[3+\frac{4}{c}\left(\frac{E S D}{d_{c}}\right)^{3-D}-3\left(\frac{8}{c}\left(\frac{E S D}{d_{c}}\right)^{3-D}-3\right)^{1 / 2}\right]^{-1 / 2}$

with $c$ the packing coefficient of an aggregate, here $c=0.25$ as in Li and Logan (2001), ESD the equivalent spherical diameter of the aggregate, $d_{c}$ the diameter of the cell and $D$ the fractal dimension of the aggregate. $D$ was calculated from the relation between sinking rate $\left(S_{\text {agg }}\right)$ and aggregate size $(E S D)$ following the relation given in Xiao et al. (2012) and related here as equation 4:

$S_{a g g} \sim E S D^{D-1}$

Excess density: The excess density $(\Delta \rho)$ of each aggregate for the three treatments was calculated as in Iversen and Ploug (2010), using the following 3 equations: the Navier-Stokes drag equation (equation 5; Stokes 1851), the drag equation for Reynolds number < 1 (equation 6; White 1974) and equation 7 that calculates the Reynolds number $(R e)$ :

$$
\begin{aligned}
& \Delta \rho=\frac{C_{D} \rho_{\varpi} S_{a g g^{2}}}{\frac{4}{3} g E S D} \\
& C_{D}=\frac{24}{R e}+\frac{6}{1+R e^{0.5}}+0.4 \\
& R e=\frac{S_{a g g} E S D \rho_{\varpi}}{\eta}
\end{aligned}
$$

In these equations, $C_{D}$ is the dimensionless drag force calculated using equation $6, \rho_{\varpi}$ is the density of the seawater at $16^{\circ} \mathrm{C}$ and a salinity of $35\left(1.0257 \mathrm{~kg} \mathrm{~L}^{-1}\right), S_{a g g}$ the aggregate sinking rate, $\mathrm{g}$ the gravitational constant $\left(981 \mathrm{~cm} \mathrm{~s}^{-2}\right)$, ESD is the aggregate equivalent spherical diameter and $\eta$ the dynamic viscosity of the seawater $\left(0.01211 \mathrm{~g} \mathrm{~cm}^{-1} \mathrm{~s}^{-1}\right.$ at $16^{\circ} \mathrm{C}$ and a salinity of 35$)$.

Transparent Exopolymer Particles (TEPs): TEP stained with alcian blue can be observed with enough contrast on a microscopic slide under microscopy without any filter (Beauvais, 2003). To reveal the presence of TEP, one aggregate of each treatment was carefully transferred to $200 \mu \mathrm{L}$ of seawater on a microscope slide. Afterwards $500 \mu \mathrm{L}$ of Alcian blue were added to each aggregate to stain transparent TEP from the aggregates according to Passow and Alldredge (1995).

\section{Statistics and regressions}

Statistics were performed with the software $R$ (R Core Team, 2013) under a level of statistical significance with p-value $<0.05$. Normality of the data and homogeneity of the variance were respectively assessed with a Shapiro and a F test. For ESD and amount of incorporated microbeads, 
the differences between the different aggregates were assessed with non-parametric Kruskal-Wallis one-way analyses of covariance. When the null-hypothesis of similarity was rejected, a post-hoc Nemenyi-Damico-Wolfe-Dunn was performed to find the group of data which display differences. This post-hoc test was performed using multcomp package (Hothorn et al., 2008) in $R$. Non-linear regressions (power law curve) between sinking rates and ESD were fitted using the software Sigmaplot.

\section{Results}

\section{Aggregate variability according to species}

The monoculture of $C$. neogracile and the mix of $C$. neogracile and $R$. salina produced the first aggregates in two days while the monoculture of $R$. salina produced the first aggregates in three days. Aggregate manipulation showed a strong difference in the cohesion of the cells constituting aggregates in the three treatments. $R$. salina aggregates tended to fall apart when handled while aggregates even partially constituted by $C$. neogracile were much more resistant to turbulence. All aggregates contained TEP as evidenced by distinct coloration of aggregates following the alcian blue addition.

In term of size distribution, equivalent spherical diameter (ESD) for C. neogracile aggregates ranged from 0.9 to $5.7 \mathrm{~mm}$ with a mean value of $3.2 \mathrm{~mm}( \pm 0.13$ Standard Error) in the nonmodified tank. The ESD for $R$. salina aggregates ranged from 1.2 to $3.5 \mathrm{~mm}$ with a mean value of $1.8 \mathrm{~mm}( \pm 0.07 \mathrm{SE})$. The mix of the two species produced aggregates with mean ESD of $3.5 \mathrm{~mm}( \pm$ $0.15 \mathrm{SE}$ ) with a range of 1.2 to $8.8 \mathrm{~mm}$. Differences in ESD between of $R$. salina and $C$. neogracile, and also between $R$. salina and the mix of species were significant (p-values < 0.001 ). No significant difference in ESD was found between $C$. neogracile and the mix (p-value $=0.17$ ).

Sinking rates $\left(\mathrm{S}_{\mathrm{agg}}\right)$ increased with the increase of the equivalent spherical diameter (ESD). As aggregates are fractal particles, regressions between ESD and sinking rates for the three types of aggregates were fitted with a power law curve (figure 2). The regression between $C$. neogracile aggregate ESD and sinking rates was $\mathrm{S}_{\mathrm{agg}}=223.1(\mathrm{ESD})^{0.646}\left(\mathrm{r}^{2}=0.57\right)$, for the $R$. salina aggregates the regression was $\mathrm{S}_{\mathrm{agg}}=44.5(\mathrm{ESD})^{0.926}\left(\mathrm{r}^{2}=0.36\right)$ and for the mix was $\mathrm{S}_{\mathrm{agg}}=53.8(\mathrm{ESD})^{0.781}\left(\mathrm{r}^{2}=\right.$ 0.59). The fractal dimension (D) of the C. neogracile aggregates estimated from the regression is 1.65. $R$. salina aggregate are slightly less fractal with a fractal dimension of 1.92 , while for the mix, the fractal dimension is intermediary $(\mathrm{D}=1.78)$. Despite different equations, the figure 2 showed 
similar relations between ESD and sinking rates for the mix and $R$. salina but with a mean and range of ESD smaller for $R$. salina than for the mix.

Excess densities have been estimated from the ESD and the $S_{\text {agg }}$ using equation 5. When plotting the excess density calculated for each aggregates versus size (ESD), the overall excess densities of C. neogracile aggregates are higher than those of $R$. salina and mix aggregates (Figure 3). As aggregates are fractal, their excess density is not linearly correlated to the size. To compare aggregate types, the average size of $2.5 \mathrm{~mm}$-aggregates was chosen as pivot value. At this size, C. neogracile aggregate average excess density was $3510^{-4} \mathrm{~kg} \mathrm{~L}^{-1}$, almost tenfold higher than excess densities of aggregates made of the mix or $R$. salina which have similar calculated values of $5.010^{-4} \mathrm{~kg} \mathrm{~L}^{-1}$ and $4.610^{-4} \mathrm{~kg} \mathrm{~L}^{-1}$, respectively. Using Brinkman equation (eq. 3), a permeability factor per aggregate has been estimated. For an average aggregate with an ESD of $2.5 \mathrm{~mm}$, the Brinkman permeability factor was $6.27,6.46$ and 8.87 for C. neogracile, the mix and $R$. salina aggregate, respectively.

\section{Characteristics of aggregates after exposure to microbeads}

The amount of incorporated microbeads at the end of the dilution phase varied significantly according to aggregate types. Concentrations of microbeads in aggregates $\left(3.610^{5} \pm 810^{4}\right.$ beads $\mathrm{mL}^{-1}$ ) from R. salina were 160 times higher than background concentration. Aggregates from the species mix concentrated the microbeads by a factor of $19\left(4.310^{4} \pm 510^{3}\right.$ beads $\left.\mathrm{mL}^{-1}\right)$ while C.neogracile aggregates concentrated microbeads by a factor of $9\left(1.9 .10^{4} \pm 510^{3}\right.$ beads $\left.\mathrm{mL}^{-1}\right)$. 
The regression between sinking rates and aggregate ESD changed upon incorporation of MP into aggregates (figure 4). Sinking rates of the aggregates from $C$. neogracile decreased after MP exposure from 473 to $165 \mathrm{~m} \mathrm{day}^{-1}$ for an aggregate with a mean size of $3.2 \mathrm{~mm}$. In contrast, sinking rate for an aggregate from $R$. salina with a mean size of $1.8 \mathrm{~mm}$ increased after MP exposure, from 76 to $125 \mathrm{~m} \mathrm{day}^{-1}$. Meanwhile sinking rates of the aggregates from the mix have just barely decreased from 144 to $122 \mathrm{~m} \mathrm{day}^{-1}$ for an aggregate with a mean size of $3.5 \mathrm{~mm}$. The microbeads incorporation slightly changes the regression between sinking rate and ESD (figure 4). For $C$. neogracile, and the mix, the regression between sinking rate and ESD for aggregate containing MP were $S_{\mathrm{agg}}=67.0(\mathrm{ESD})^{0.778}\left(\mathrm{r}^{2}=0.78\right)$ and $\mathrm{S}_{\mathrm{agg}}=37.1(\mathrm{ESD})^{0.938}\left(\mathrm{r}^{2}=0.6\right)$, respectively. From these non linear regressions, the fractal dimension can be calculated using equation 4. The fractal dimension of aggregates containing diatoms slightly increased upon the incorporation of microbeads, from 1.65 to 1.78 and from 1.78 to 1.94 , respectively. For $R$. salina, $\mathrm{S}_{\mathrm{agg}}=78$ (ESD) ${ }^{0.82}$ $\left(r^{2}=0.3\right)$, which gives a fractal dimension of 1.82 slightly lower than non-exposed aggregates $(\mathrm{D}=$ 1.92). Overall, when microbeads are incorporated, all aggregate types became slightly less fractal.

Incorporation of microbeads also changed aggregate permeabilities and excess densities of aggregates. The Brinkman permeability factor increased after microbead incorporation for $C$. neogracile and the mix aggregates. An average diatom aggregate with an ESD of $3.2 \mathrm{~mm}$ has a Brinkman permeability factor $(\xi)$ of 9.86 and of 6.77 with and without microbeads. For a mix aggregate of $3.5 \mathrm{~mm}, \xi$ increased from 7.34 to 10.86 upon microbead incorporation. At the opposite, for an average $R$. salina aggregate of $1.8 \mathrm{~mm}$, $\xi$ decreased from 7.75 to 6.22 . Upon incorporation of microbeads, average calculated excess densities of C.neogracile aggregates decreased (figure 5), i.e. for an aggregate of $3.2 \mathrm{~mm}$ average ESD, its excess density decreased from $2.810^{-3}$ to $5.710^{-4} \mathrm{~kg} \mathrm{~L}^{-1}$. On the contrary, excess density of $R$. salina aggregates increased when microbeads are incorporated (figure 5). A $R$. salina aggregate of $1.8 \mathrm{~mm}$ average ESD had excess densities of $1.210^{-3}$ and $0.710^{-3} \mathrm{~kg} \mathrm{~L}^{-1}$ with and without microbeads, respectively. The calculated excess density of mix aggregate with an average ESD of $3.5 \mathrm{~mm}$ varied little with values of $3.010^{-4}$ and $3.910^{-4} \mathrm{~kg} \mathrm{~L}^{-1}$ with and without microbeads (figure 5).

\section{Discussion}

\section{Aggregation}

Diatoms excrete high quantities of sticky TEP in comparison with other species (Passow, 2002), and some diatoms are chain forming. This is the case of most Chaetoceros sp. that have biogenic silica spines and Chaetoceros neogracile is no exception. For these two reasons, C. neogracile is 
known to easily aggregate. In our experiment, $R$. salina also produced some TEP as shown by the alcian blue coloration of the $R$. salina culture and aggregates, which may explain the good aggregation of this species in our study. The general size of aggregates produced is consistent with those of aggregates from other in vitro experiments (Ploug et al., 2002; Ploug et al., 2008; Schmidt et al., 2013) and those sampled and observed in situ (Alldredge et al., 1988; Kiørboe et al., 1998). Their specific characteristics, however, varied with the species composition of microalgae aggregates. Mean size and size distribution of aggregates of $C$. neogracile and of the mixture of the two species were larger than those of $R$. salina aggregates. It may reflect that $C$. neogracile were forming more solid chains due to their spines and/or that TEP of $C$. neogracile and $R$. salina were different in terms of physical/chemical characteristics and concentrations (Bhaskar et al., 2005; Passow, 2002). A previous study relates aggregate size to stickiness (Passow, 2002). Accordingly, the bigger aggregates containing $C$. neogracile may be stickier, which may also be consistent with their greater resistance to disturbance when handled. Also, the capacity of the diatom C. neogracile to form long chains and the presence of their spines probably may both have an impact on general size and resistance of these aggregates. Addition of $C$. neogracile to $R$. salina produced bigger and more resistant aggregates than aggregates only constituted by $R$. salina even though $R$. salina was predominant in the mixture used to promote aggregation.

The three types of aggregates are fractal, as showed by their sinking rate that increased with size according to power low curve, defined as $\mathrm{A}(\mathrm{ESD})^{\mathrm{B}}$ with $\mathrm{B}<1$. While the size of the mix is close to those of $C$. neogracile aggregates, the $\mathrm{S}_{\mathrm{agg}}=\mathrm{f}(\mathrm{ESD})$ curve of mix is similar to this of $R$. salina (figure 2). Higher mean sinking rate of the mix aggregates as compared to $R$. salina is likely due to their greater size. Diatom aggregates were definitively sinking faster (up to 800 meters day ${ }^{-1}$ ). In many studies, the fast sinking of diatom aggregates is explained by density of diatom cells, ballasted by their frustule made of biogenic silica. Biogenic opal is denser $\left(\sim 2.070 \mathrm{~kg} \mathrm{~L}^{-1}\right)$ than organic matter (from $\sim 0.860 \mathrm{~kg} \mathrm{~L}^{-1}$ for lipids to $\sim 1.500 \mathrm{~kg} \mathrm{~L}^{-1}$ for carbohydrates) (Boyd et al., 2002; De La Rocha et al., 2000; Hutchins et al., 1998). Size and density are not the only factor driving the sinking rates of phytoplankton aggregates. As discussed earlier, aggregates are not perfectly spherical, they are fractal (De la Rocha et al., 2007; Kilps et al., 1994; Logan et al., 1990) and porous particles (Iversen et al., 2010; Ploug et al., 2002; Stolzenbach et al., 1993). Porosity and permeability impact sinking rate (Xiao et al., 2012, Li and Yuan, 2002) and increase with size due to fractal dimension. Larger aggregates have more macropores in which water can flow through easier increasing thus settling velocity of aggregates by decreasing drag forces (Li and Yuan, 2002). Permeability of fractal aggregates also varied according to their constitution. The permeability factors calculated using the Brinkman equation are similar for mix and C. neogracile aggregates with the same ESD but higher for $R$. salina. Such a calculated lower permeability of the mix 
aggregates suggests that other factors counterbalanced this difference. A decrease of the aggregate porosity due to the mixture of species or another physico-chemical parameter or biochemical interaction between both microalgae species may have resulted in the unexpected lower sinking rates of mix aggregates.

\section{Aggregates and microplastics}

Despite different chemical, biological and physical characteristics all three types of aggregates concentrated microbeads. The extent to which they did so, however, was not the same. Aggregates of $R$. salina showed a higher affinity for microbeads, incorporating eighteen times more microbeads per $\mathrm{ml}$ of aggregate than $C$. neogracile aggregates. At first view it seems unexpected considering that lower stickiness and sinking rate as well as lower number of particle would reduce collision rate which was demonstrated to decrease incorporation of smaller particles as proposed by Jackson et al. (1998). But considering that $R$. salina aggregates are both more permeable and more fragile than C.neogracile aggregates, two possible hypotheses may explain such high microbeads incorporation by $R$. salina. First, increase of aggregate permeability enhance encountering between small particles and aggregates as the small particles are not moved away from the aggregate by Brownian motions but can go through aggregates macropores and be captured (Xiao et al., 2012; Kiørboe, 2008). Second, fragility and thus plasticity of the $R$. salina aggregates may provoke constant breakage and rearrangement. When an aggregate breaks, new surfaces and macropores become available for microbeads to stick to and a succession of fragmentation and coagulation would permit the incorporation of microbeads in the whole aggregate volume and not only at the surface or in macropores.

Once incorporated, microbeads impacted aggregate sinking rates. For the dense, fast-sinking diatom aggregates, sinking rates decreased substantially. When the low density microbeads $\left(1.050 \mathrm{~kg} \mathrm{~L}^{-1}\right)$ became concentrated in diatom aggregates, the overall density of the aggregates decreased and may have resulted in lower excess density and sinking rates. Meantime, the estimated permeability of the MP exposed $C$. neogracile aggregate increased as compared to non-exposed aggregate. As increased permeability is generally associated to a decrease of the drag forces and thus to an increase of sinking rate, this suggests that decreased excess density largely overcame permeability change in modulating sinking rates. In contrast to $C$. neogracile aggregates, sinking rates of $R$. salina aggregates exposed to MP slightly increased. Calculated excess densities followed the same trend, i.e. increasing after microbead incorporation, suggesting that $R$. salina cells may have a density even lower than the microbeads. In parallel a decrease of their permeability has been calculated. As for C. neogracile aggregates, excess density changes counteracts permeability changes. Overall, while it needs to be confirmed by direct measurements, for both types of 
monoculture aggregates excess density changes due to microbead incorporation may control the impact of MP on aggregate sinking rates.

\section{Implications for the global ocean}

The affinity of $R$. salina and $C$. neogracile for the microbeads supports the idea that phytoplankton aggregates act as a potential MP sink. Once incorporated, the sinking rates of MP in aggregates could reach several hundred meters per day. In comparison, the sinking rate of free beads $(2 \mu \mathrm{m}$ beads of polystyrene, density of $1050 \mathrm{~kg} \mathrm{~L}^{-1}$ ), due to their small size, is under $4 \mathrm{~mm} \mathrm{~d}^{-1}$. Interestingly, when considering concentrations of microbeads in aggregates and their impact on sinking rates, $R$. salina aggregates would be a better candidate to export MP than diatom aggregates. However, as $R$. salina aggregates are quite fragile, they may not exist or quickly break in oceanic conditions, with turbulences and flux feeders (Alldredge et al., 1988, Green and Dagg, 1997). Furthermore, monospecific aggregates unlikely exist in situ and a small proportion of diatom may increase overall resistance and size of phytoplankton aggregates. Once incorporated to phytoplankton aggregates, MP might also be exported out of the surface layers via fast-sinking faecal pellets as evidenced by Cole et al. (2013) as MP particles would be more approachable for zooplankton. Although more experiments and measurements are needed to consider marine aggregates and environmental MP diversity in term of size, density and physical/chemical characteristics, our results showed that aggregates are good candidates to transport of MP out of the surface layer. This may at least partially explain the lack of sea surface plastics found by Cózar et al. (2014) and Eriksen et al. (2014) and the higher concentrations found on the oceanic floor (Woodall et al., 2014).

The role of MP in the fate of aggregates may vary depending on the MP size, density and composition. The MP particles used in this study, when incorporated into marine aggregates, may have an impact on sinking rate by changing aggregates features (density, permeability...). The concentrations used here is high compare to those measured in situ for larger microplastics but to our knowledge, no quantification of such small MP, either as number or as mass concentration, is yet available in the field. It is generally believed that concentrations of smaller particles may be higher than those of larger particles (Cózar et al., 2014). However, when exposed to this microplastic concentrations, a strong decrease in diatom aggregates sinking rates was observed, suggesting that MP contamination may have an impact on export efficiency in highly contaminated area such consequence obviously deserves further investigation. 
The impact on marine organisms can become significant if marine aggregates contain more plastics than the surrounding water, as observed in our study. Incorporation of MP into marine aggregates may change MP bioavailability for marine organisms. Marine snow is the main source of carbon for flux feeders and the increased MP concentration in aggregates means that such organisms would have a higher exposure to plastics. As a consequence of MP transport via aggregates to the benthos, benthic organisms could also be impacted. Ward and Kach (2009) demonstrated that polystyrene nanoparticles were more easily ingested by filter feeders when associated to aggregates, implying a change in the bioavailability for these organisms. As in Cózar et al. (2014), different levels of the food web need to be examined in search of the missing plastics, and the flux feeders are a good place to start. Marine aggregates are also known to host microbial communities in higher concentrations than the surrounding water (Alldredge et al., 1988; Smith et al., 1992) and with intense enzyme activity (Smith et al., 1992). Considering that bacterial populations may contribute to MP degradation (Zettler et al., 2013), marine aggregates could be a place for their bacterial degradation.

\section{Conclusion}

For the purpose of this research that was to investigate the impact of marine aggregates on MP fate, we built a new device to study interactions between aggregates and MP, a flow-through roller tank. This device allows the circulation of a flow through the tank to change medium characteristics during sedimentation. With the really weak flow used in here, the aggregates exposed were not deflected and appeared morphologically similar. While future studies may benefit from more investigations on the impact of flow on aggregates, we believe that this new system may be very useful for studies on sinking particles.

Vertical transport of MP by phytoplankton aggregates is likely one of the MP sinks the scientific community is missing to explain the low MP concentrations measured in the ocean surface. It clearly supports the hypothesis that deep sea may be a major sink for MP (Woodall et al., 2014). Insitu measurements of MP concentrations are crucial, not only on surface, but throughout the water column and on the seafloor, in order to better understand the MP cycle and its link with other biogeochemical cycles. 


\section{Acknowledgments}

This work was carried out within the frame of the MICRO project (EU INTERREG IVA - Seas (MICRO 09-002-BE)). We would also like to acknowledge the help of Michael Pantalos for English vocabulary and grammar corrections. 


\section{References}

Alldredge, A.L. and Silver, M.W., 1988. Characteristics, dynamics and significance of marine snow. Progress in Oceanography, 20(1): 41-82.

Andrady, A.L., 2011. Microplastics in the marine environment. Marine Pollution Bulletin, 62(8): 1596-1605.

Ballent, A., Pando, S., Purser, A., Juliano, M.F. and Thomsen, L., 2013. Modelled transport of benthic marine microplastic pollution in the Nazare Canyon. Biogeosciences, 10(12): 79577970 .

Barnes, D.K.A., Galgani, F., Thompson, R.C. and Barlaz, M., 2009. Accumulation and fragmentation of plastic debris in global environments. Philosophical Transactions of the Royal Society B-Biological Sciences, 364(1526): 1985-1998.

Barnes, D.K.A. and Milner, P., 2005. Drifting plastic and its consequences for sessile organism dispersal in the Atlantic Ocean. Marine Biology, 146(4): 815-825.

Beauvais, S., 2003. Étude des Particules Exopolymériques Transparentes (TEP) en milieu marin. Dynamique et rôle dans le cycle du carbone.

Bhaskar, P.V. and Bhosle, N.B., 2005. Microbial extracellular polymeric substances in marine biogeochemical processes. Current Science, 88(1): 45-53.

Bhattacharya, P., Lin, S.J., Turner, J.P. and Ke, P.C., 2010. Physical Adsorption of Charged Plastic Nanoparticles Affects Algal Photosynthesis. Journal of Physical Chemistry C, 114(39): 16556-16561.

Boerger, C.M., Lattin, G.L., Moore, S.L. and Moore, C.J., 2010. Plastic ingestion by planktivorous fishes in the North Pacific Central Gyre. Marine Pollution Bulletin, 60(12): 2275-2278.

Boyd, C. and Gradmann, D., 2002. Impact of osmolytes on buoyancy of marine phytoplankton. Marine Biology, 141(4): 605-618.

Carson, H.S., 2013. The incidence of plastic ingestion by fishes: From the prey's perspective. Marine pollution bulletin, 74(1): 170-174.

Chou, L. and Wollast, R., 1984. Study of the weathering of albite at room temperature and pressure with a fluidized bed reactor. Geochimica et Cosmochimica Acta, 48(11): 2205-2217.

Claessens, M., Meester, S.D., Landuyt, L.V., Clerck, K.D. and Janssen, C.R., 2011. Occurrence and distribution of microplastics in marine sediments along the Belgian coast. Marine pollution bulletin, 62(10): 2199-2204.

Cole, M. et al., 2013. Microplastic Ingestion by Zooplankton. Environmental Science \& Technology, 47(12): 6646-6655.

Collignon, A. et al., 2012. Neustonic microplastic and zooplankton in the North Western Mediterranean Sea. Marine Pollution Bulletin, 64(4): 861-864. 
Cózar, A. et al., 2014. Plastic debris in the open ocean. Proceedings of the National Academy of Sciences: 201314705.

Dantas, D.V., Barletta, M. and da Costa, M.F., 2012. The seasonal and spatial patterns of ingestion of polyfilament nylon fragments by estuarine drums (Sciaenidae). Environmental Science and Pollution Research, 19(2): 600-606.

De La Rocha, C.L., Hutchins, D.A., Brzezinski, M.A. and Zhang, Y.H., 2000. Effects of iron and zinc deficiency on elemental composition and silica production by diatoms. Marine Ecology Progress Series, 195: 71-79.

De La Rocha, C.L. and Passow, U., 2007. Factors influencing the sinking of POC and the efficiency of the biological carbon pump. Deep Sea Research Part II: Topical Studies in Oceanography, 54(5): 639-658.

Deltares, 2011. Marine Litter in the Dutch Marine environment. Final report, 105pp.

Desforges, J.-P.W., Galbraith, M., Dangerfield, N. and Ross, P.S., 2014. Widespread distribution of microplastics in subsurface seawater in the NE Pacific Ocean. Marine pollution bulletin, 79(1): 94-99.

Engel, A., 2000. The role of transparent exopolymer particles (TEP) in the increase in apparent particle stickiness $(\alpha)$ during the decline of a diatom bloom. Journal of Plankton Research, 22(3): 485-497.

EPA, U., 2006. Municipal Solid Waste in the United States: 2005 facts and figures. EPA530-R-06011, United States Environmental Protection Agency, Office of Solid Waste, Washington, DC.

Eriksen, M. et al., 2014. Plastic Pollution in the World's Oceans: More than 5 Trillion Plastic Pieces Weighing over 250,000 Tons Afloat at Sea. PLoS ONE, 9(12): e111913.

Eriksson, C. and Burton, H., 2003. Origins and biological accumulation of small plastic particles in fur seals from Macquarie Island. AMBIO: A Journal of the Human Environment, 32(6): 380-384.

Farrell, P. and Nelson, K., 2013. Trophic level transfer of microplastic: Mytilus edulis (L.) to Carcinus maenas (L.). Environmental Pollution, 177: 1-3.

Fossi, M.C. et al., 2012. Are baleen whales exposed to the threat of microplastics? A case study of the Mediterranean fin whale Balaenoptera physalus. Marine pollution bulletin, 64(11): 2374-2379.

Graham, E.R. and Thompson, J.T., 2009. Deposit- and suspension-feeding sea cucumbers (Echinodermata) ingest plastic fragments. Journal of Experimental Marine Biology and Ecology, 368(1): 22-29.

Green, E.P. and Dagg, M.J., 1997. Mesozooplankton associations with medium to large marine snow aggregates in the northern Gulf of Mexico. Journal of Plankton Research, 19(4): 435447. 
Guillard, R.R.L., 1975. Culture of phytoplankton for feeding marine invertebrates, Culture of marine invertebrate animals. Springer, pp. 29-60.

Hillebrand, H., Dürselen, C.D., Kirschtel, D., Pollingher, U. and Zohary, T., 1999. Biovolume calculation for pelagic and benthic microalgae. Journal of Phycology, 35(2): 403-424.

Hothorn, T., Bretz, F. and Westfall, P., 2008. Simultaneous Inference in General Parametric Models. Biometrical Journal, 50(3): 346 - 363.

Hutchins, D.A. and Bruland, K.W., 1998. Iron-limited diatom growth and Si: N uptake ratios in a coastal upwelling regime. Nature, 393(6685): 561-564.

Iversen, M.H., Nowald, N., Ploug, H., Jackson, G.A. and Fischer, G., 2010. High resolution profiles of vertical particulate organic matter export off Cape Blanc, Mauritania: Degradation processes and ballasting effects. Deep Sea Research Part I: Oceanographic Research Papers, 57(6): 771-784.

Iversen, M.H., Ploug, H., 2010. Ballast minerals and the sinking carbon flux in the ocean: carbonspecific respiration rates and sinking velocities of macroscopic organic aggregates (marine snow). Biogeosciences Discuss. 7, 3335-3364.

Jackson, G.A. and Burd, A.B., 1998. Aggregation in the marine environment. Environmental science \& technology, 32(19): 2805-2814.

Jantz, L.A., Morishige, C.L., Bruland, G.L. and Lepczyk, C.A., 2013. Ingestion of plastic marine debris by longnose lancetfish Alepisaurus ferox in the North Pacific Ocean. Marine pollution bulletin, 69(1): 97-104.

Kilps, J.R., Logan, B.E. and Alldredge, A.L., 1994. Fractal dimensions of marine snow determined from image analysis of in situ photographs. Deep Sea Research Part I: Oceanographic Research Papers, 41(8): 1159-1169.

Kranck, K. and Milligan, T., 1988. Macroflocs from diatoms: in situ photography of particles in Bedford Basin, Nova Scotia. Marine ecology progress series. Oldendorf, 44(2): 183-189.

Kiørboe, T., Tiselius, P., Mitchell-Innes, B., Visser, A.W. and Mari, X., 1998. Intensive aggregate formation with low vertical flux during an upwelling-induced diatom bloom. Limnol. Oceanogr, 43: 104-116.

Kiørboe, T., 2008. A Mechanistic Approach to Plankton Ecology. Princeton University Press.

Law, K.L. et al., 2010. Plastic accumulation in the North Atlantic subtropical gyre. Science, 329(5996): 1185-1188.

Li, X.-Y. and Logan, B.E., 2001. Permeability of fractal aggregates. Water research, 35(14): 33733380 .

Li, X.Y. and Yuan, Y.A., 2002. Settling velocities and permeabilities of microbial aggregates. Water Research, 36(12): 3110-3120.

Lima, A.R.A., Costa, M.F. and Barletta, M., 2014. Distribution patterns of microplastics within the plankton of a tropical estuary. Environmental research, 132: 146-155. 
Logan, B.E. and Wilkinson, D.B., 1990. Fractal geometry of marine snow and other biological aggregates. Limnology and Oceanography, 35(1): 130-136.

Long, M., Hégaret, H., Lambert, C., Le Goic, N., Huvet, A., Sussarellu , R., Fabioux, C., Soudant, P. (2014). Can phytoplankton species impact microplastic behaviour within water column? International workshop abstract book - Fate and impacts of microplastics in marine ecosystems. Page 9. January 2014. Plouzané.

Marie, D., Brussaard, C.P.D., Thyrhaug, R., Bratbak, G. and Vaulot, D., 1999. Enumeration of marine viruses in culture and natural samples by flow cytometry. Applied and Environmental Microbiology, 65(1): 45-52.

Mohamed Nor, N.H. and Obbard, J.P., 2014. Microplastics in Singapore's coastal mangrove ecosystems. Marine pollution bulletin, 79(1): 278-283.

Moriceau, B., Garvey, M., Passow, U. and Ragueneau, O., 2007. Evidence for reduced biogenic silica dissolution rates in diatom aggregates. Marine Ecology Progress Series, 333: 129-142.

Norén, F. (2007). Small plastic particles in Coastal Swedish waters. KIMO Sweden.

Passow, U., 2002. Transparent exopolymer particles (TEP) in aquatic environments. Progress in Oceanography, 55(3-4): 287-333.

Passow, U. and Alldredge, A.L., 1995. A dye-binding assay for the spectrophotometric measurement of transparent exopolymer particles (TEP). Limnology and Oceanography, 40(7): 1326-1335.

Ploug, H., Hietanen, S. and Kuparinen, J., 2002. Diffusion and advection within and around sinking, porous diatom aggregates. Limnology and oceanography, 47(4): 1129-1136.

Ploug, H., Iversen, M. and Fischer, G., 2008. Ballast, sinking velocity and apparent diffusivity in marine snow and zooplankton fecal pellets: Implications for substrate turnover by attached bacteria. Limnol. Oceanogr. 53 (5): 1878-1886.

Ploug, H., Terbruggen, A., Kaufmann, A., Wolf-Gladrow, D. and Passow, U., 2010. A novel method to measure particle sinking velocity in vitro, and its comparison to three other in vitro methods. Limnology and Oceanography-Methods, 8: 386-393.

Rickert, D., Schlüter, M. and Wallmann, K., 2002. Dissolution kinetics of biogenic silica from the water column to the sediments. Geochimica et Cosmochimica Acta, 66(3): 439-455.

Schmidt, K., De La Rocha, C.L., Gallinari, M. and Cortese, G., 2013. Not all calcite ballast is created equal: differing effects of foraminiferan and coccolith calcite on the formation and sinking of aggregates. Biogeosciences Discussions, 10(9).

Shanks, A.L. and Edmondson, E.W., 1989. Laboratory-made artificial marine snow: a biological model of the real thing. Marine Biology, 101(4): 463-470.

Smith, D.C., Simon, M., Alldredge, A. L., Azam, F. 1992. Intense hydrolytic enzyme activity on marine aggregates and implications for rapid particle dissolution. Nature, 359: 10. 
Staats, N., Stal, L.J. and Mur, L.R., 2000. Exopolysaccharide production by the epipelic diatom Cylindrotheca closterium: effects of nutrient conditions. Journal of Experimental Marine Biology and Ecology, 249(1): 13-27.

Stokes, G.G., 1851. On the effect of the internal friction of fluids on the motion of pendulums, 9. Pitt Press.

Stolzenbach, K.D., 1993. Scavenging of small particles by fast-sinking porous aggregates. Deep Sea Research Part I: Oceanographic Research Papers, 40(2): 359-369.

Thompson, R.C. et al., 2004. Lost at sea: Where is all the plastic? Science, 304(5672): 838-838.

Thornton, D., 2002. Diatom aggregation in the sea: mechanisms and ecological implications. European Journal of Phycology, 37(2): 149-161.

Turner, J.T., 2002. Zooplankton fecal pellets, marine snow and sinking phytoplankton blooms. Aquatic Microbial Ecology, 27(1): 57-102.

Underwood, G.J.C., Boulcott, M., Raines, C.A. and Waldron, K., 2004. Environmental effects on exopolymer production by marine benthic diatoms: dynamics, changes in composition, and pathways of production1. Journal of Phycology, 40(2): 293-304.

Van Cappellen, P. and Qiu, L., 1997. Biogenic silica dissolution in sediments of the Southern Ocean. I. Solubility. Deep Sea Research Part II: Topical Studies in Oceanography, 44(5): 1109-1128.

Van Cauwenberghe, L., Claessens, M., Vandegehuchte, M., Mees, J. and Janssen, C., 2014. Assessment of marine debris on the Belgian Continental Shelf. International workshop abstract book - Fate and impacts of microplastics in marine ecosystems. Page 7. January 2014. Plouzane, FRANCE.

Van Cauwenberghe, L., Vanreusel, A., Mees, J. and Janssen, C.R., 2013. Microplastic pollution in deep-sea sediments. Environmental Pollution, 182: 495-499.

Ward, J.E. and Kach, D.J., 2009. Marine aggregates facilitate ingestion of nanoparticles by suspension-feeding bivalves. Marine Environmental Research, 68(3): 137-142.

White, F.M., 1979. Viscous fluid flow, 1974. McGraw-Hill, New York.

Woodall, L.C., Sanchez-Vidal, A., Canals, M., Paterson, G.L.J., Coppock, R., Sleight, V., Calafat, A., Rogers, A. D., Narayanaswamy, B. E., Thompson, R. C.. The deep sea is a major sink for microplastic debris. Royal Society open science. 1: 140317.

Wright, S.L., Thompson, R.C. and Galloway, T.S., 2013. The physical impacts of microplastics on marine organisms: A review. Environmental Pollution, 178(0): 483-492.

Xiao, F., Li, X.Y., Lam, K.M. and Wang, D.S., 2012. Investigation of the hydrodynamic behavior of diatom aggregates using particle image velocimetry. Journal of Environmental SciencesChina, 24(7): 1157-1164. 
Zettler, E.R., Mincer, T.J. and Amaral-Zettler, L.A., 2013. Life in the "plastisphere": microbial communities on plastic marine debris. Environmental science \& technology, 47(13): 71377146. 
Figure 1 : Photograph of a flow-through roller tank. Input and output are diametrically opposed for a better mixing. The flows are illustrated by the two arrows.

Figure 2: Sinking rate $(\mathrm{m} / \mathrm{d})$ versus size (ESD in $\mathrm{mm}$ ) for MP-free aggregates from the nonmodified tanks. Dots represent aggregates from $C$. neogracile, diamonds the aggregates from $R$. salina and squares the aggregates from the mix of both species. Lines represent the power law curve fitting using equation $\mathrm{A}(\mathrm{ESD}){ }^{\mathrm{B}}$. For $C$. neogracile $\mathrm{A}=223.1 \pm 0.8, \mathrm{~B}=0.646 \pm 0.003\left(\mathrm{r}^{2}=0.57, \mathrm{n}\right.$ = 52), for $R$. salina $\mathrm{A}=44.5 \pm 0.2, \mathrm{~B}=0.926 \pm 0.006\left(\mathrm{r}^{2}=0.36, \mathrm{n}=56\right)$, and the mix $\mathrm{A}=53.8 \pm$ $0.2, \mathrm{~B}=0.781 \pm 0.002\left(\mathrm{r}^{2}=0.59, \mathrm{n}=78\right)$. Parameters $\mathrm{A}$ and $\mathrm{B}$ are given with their $95 \%$ confidence limit

Figure 3 : Excess density (kg/L) versus size (ESD in $\mathrm{mm}$ ) for MP-free aggregates from the nonmodified tanks. Dots represent aggregates from $C$. neogracile, diamonds the aggregates from $R$. salina and squares the aggregates from the mix of both species.

Figure 4 : Sinking rate $(\mathrm{m} / \mathrm{d})$ versus size $(\mathrm{ESD}$ in $\mathrm{mm}$ ) for both MP-free aggregates from the nonmodified tanks (unfilled markers and dotted lines) and MP-containing aggregates from the flowthrough roller tanks (solid markers and lines). Dots represent aggregates from C. neogracile, diamonds the aggregates from $R$. salina and squares the aggregates from the mix of both species. Power law regressions equation showed by the dotted and solid line are given by the equation $\mathrm{A}$ (ESD) ${ }^{\mathrm{B}}$. For MP-containing aggregates from the flow-through roller tank, regression parameters were : $C$. neogracile $\mathrm{A}=67.0 \pm 0.2, \mathrm{~B}=0.778 \pm 0.002\left(\mathrm{r}^{2}=0.78, \mathrm{n}=74\right), R$. salina $\mathrm{A}=78.1 \pm 0.3$, $\mathrm{B}=0.822 \pm 0.005\left(\mathrm{r}^{2}=0.30, \mathrm{n}=59\right)$, and the mix $\mathrm{A}=37.1 \pm 0.1, \mathrm{~B}=0.938 \pm 0.003\left(\mathrm{r}^{2}=0.6, \mathrm{n}=\right.$ 88). Parameters A and B are given with their $95 \%$ confidence limit.

Figure 5 : Excess density ( $\mathrm{kg} / \mathrm{L})$ versus size $(\mathrm{ESD}$ in $\mathrm{mm}$ ) for both MP-free aggregates from the non-modified (unfilled markers) and MP-containing aggregates flow-through roller tanks (solid markers). Dots represent aggregates from $C$. neogracile, diamonds the aggregates from $R$. salina and squares the aggregates from the mix of both species. Dots represent aggregates from $C$. neogracile, diamonds the aggregates from $R$. salina and squares the aggregates from the mix of both species.. 
Figure 1

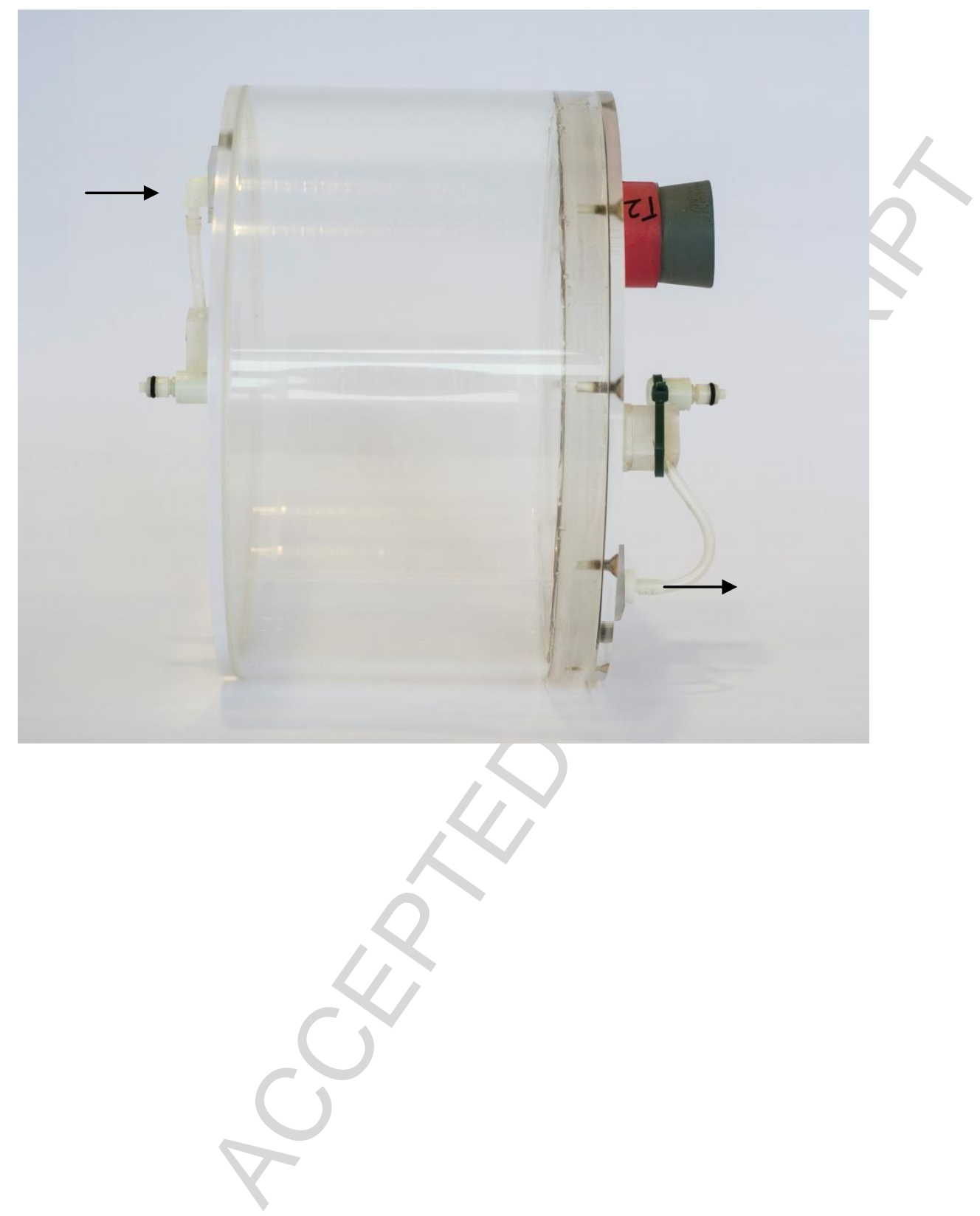


Figure 2

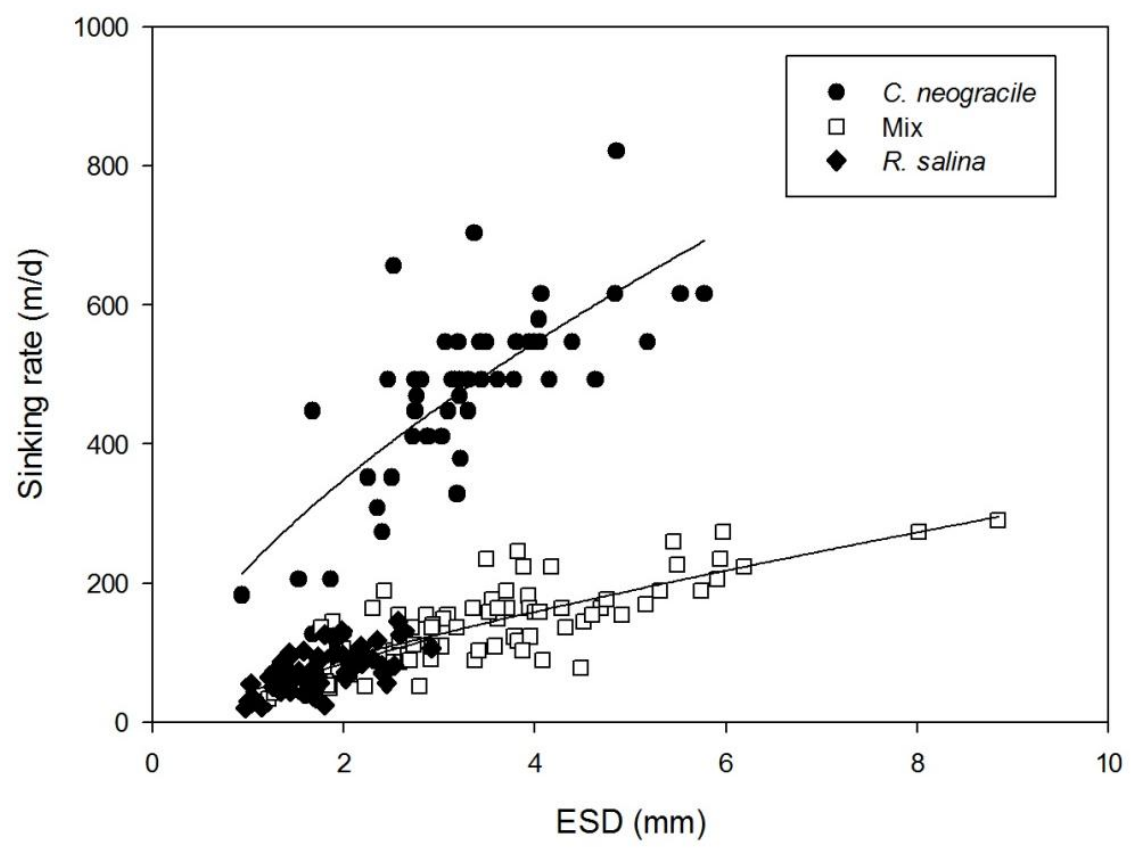


Figure 3

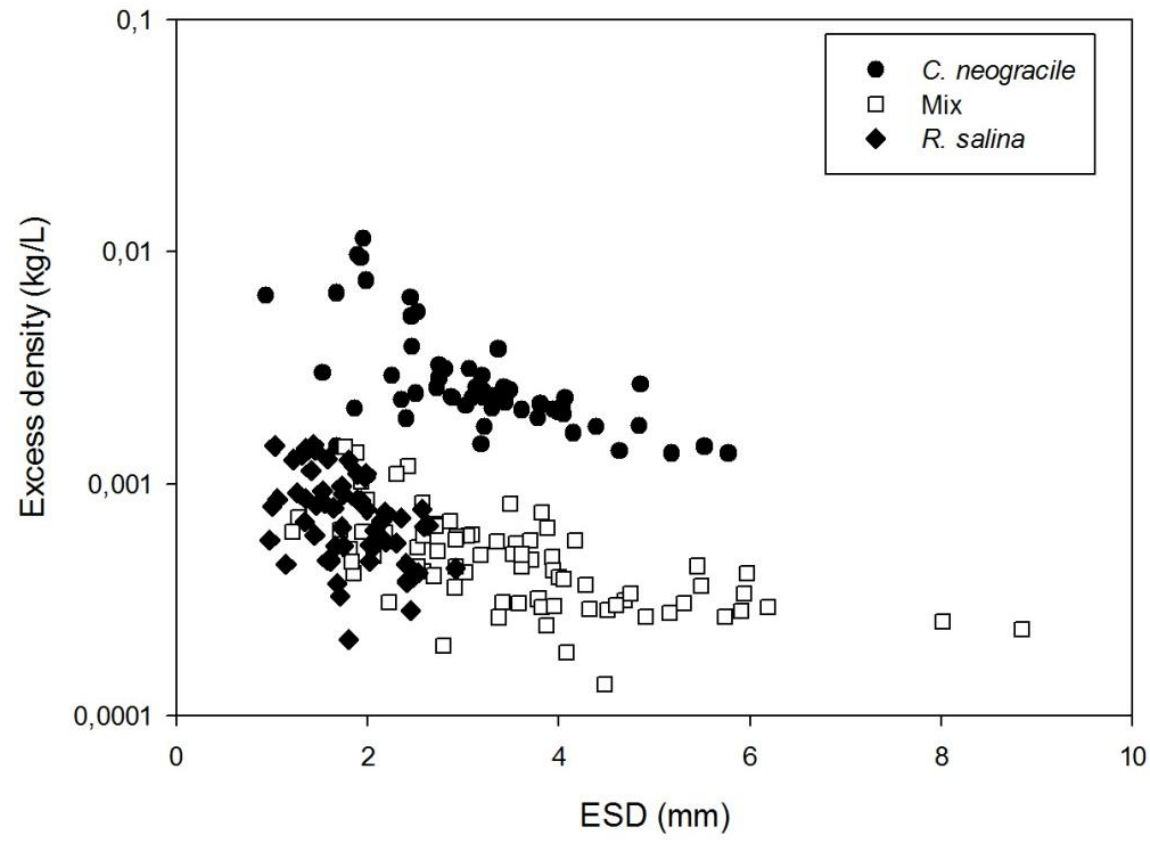


Figure 4
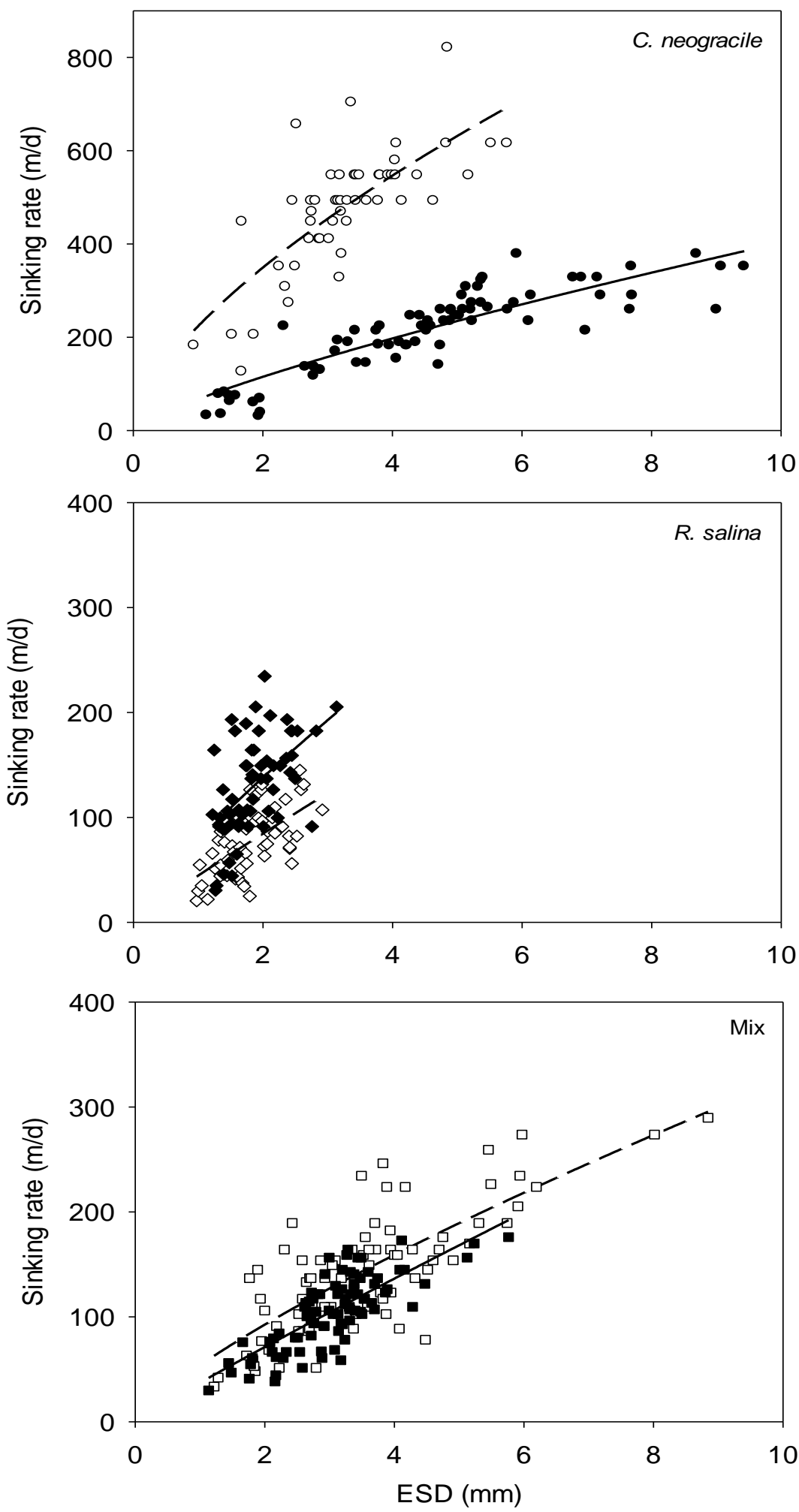
Figure 5
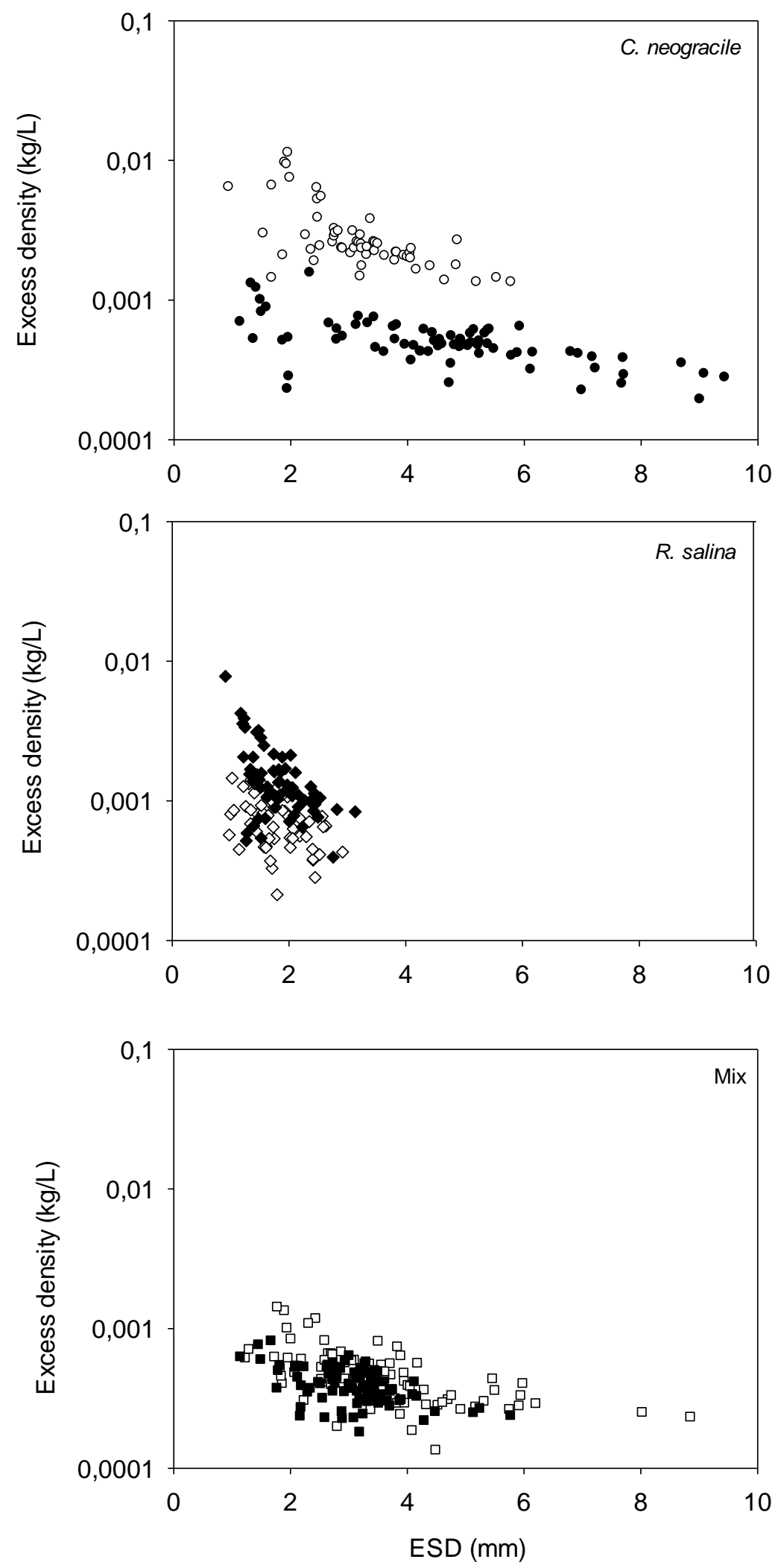